\title{
EVALUATION OF AN INTEROCCLUSAL ACRYLIC BLOCK FOR PREVENTION OF POST-RADIATION TRISMUS
}

\author{
Hesham Abdel Motaleb", Mostafa El-Gengehi" ${ }^{* *}$, Ehab Khalii ${ }^{* * * *}$ and Emad Saeed Helmy ${ }^{* * * *}$
}

\begin{abstract}
Aim: The aim of this study is to evaluate the efficacy of an interocclusal acrylic bite block as a preventative and conservative tool to prevent or minimize post radiation trismus in an effort to improve the quality of life of irradiated patients.

Patients and Methods: Twenty patients with confirmed newly diagnosed head and neck cancer planned for radiation therapy, were selected. A custom-made inter occlusal acrylic splint was fabricated for each patient before radiation therapy started. Physiotherapy - using the acrylic block and assisted range of motion exercises - were instructed for the patients during the first 12 months following end of radiation therapy. Maximum Interincisal openings were recorded prior to initiation of radiation therapy and then readings were taken monthly after completion of radiation therapy for 12 months.
\end{abstract}

Results: All patients except one have shown decrease in inter incisal openings. The decrease was statistically insignificant and non-of the patients included in this study exhibited trismus.

Conclusion: In this observational study the use of the inter occlusal acrylic block has shown promise in preventing post radiation trismus in addition to being cost effective. Further studies with more standardization and randomization are required to further prove the efficacy of this method.

\section{INTRODUCTION}

Radiation induced trismus is one of the late complications of radiation therapy which start to manifest itself three to six months after completion of radiation therapy and could worsen for up to two years ${ }^{(1,2)}$. Trismus is defined as restriction of maximum interincisal opening $(\mathrm{MIO}) \leq 35 \mathrm{~mm}$ in dentate and $\leq 40 \mathrm{~mm}$ in edentulous patients ${ }^{(3,4)}$. Normal mouth opening in males range from $38.74 \mathrm{~mm}$ to $67.27 \mathrm{~mm}$ and in females ranges from $39.4 \mathrm{~mm}$ to $60.45 \mathrm{~mm}^{(5)}$.

\footnotetext{
* Department of Oral and Maxillofacial Surgery, Nasser Institute for Research and Treatment ** Department of Oral and Maxillofacial Surgery, Faculty of Dentistry, Cairo University *** Departement of Radiotherapy and Nuclear Medicine, National Cancer Institute, Cairo University **** Department of Oral and Maxillofacial Surgery, Faculty of Dentistry, Cairo University
} 
Trismus reduces quality of life as it affects nutritional intake, oral hygiene and speech. Trismus will make intubating patients for any surgical procedure difficult. It also hinders the physicians from clinically examining the patients intraorally and could lead to missing any recurrence ${ }^{(2,3,6,7,8)}$.

Factors that influence radiation induced trismus include; radiation dose ${ }^{(2,6,7)}$, inclusion of the muscles of mastication in the radiation field ${ }^{(9,10,11,12)}$, the type of radiation taken.Use of intensity modulated radiation therapy has shown less incidence of trismus than use of conventional radiation therapy $(7,8,12,13)$.

Treatment of post radiation trismus is difficult and there is no evidence to this time on how to effectively prevent or treat it ${ }^{(14)}$. Physiotherapy is the most widely used treatment modality for radiation induced trismus. It is done using a variety of devises that forcefully open the mouth such as stacking of tongue depressors, cork screw devices, therabite jaw motion rehabilitation device and the dynasplint trismus system ${ }^{(15)}$.

Patient morale, psychological status and compliance to physiotherapy are the most important factors that affect improvement and outcome of physiotherapy. Uncompliant patients show negligible progress even after using different modalities ${ }^{(15-19)}$.

Surgery is always reserved as a last resort in treating radiation induced trismus. It is only considered when treating refractory patients who underwent physiotherapy without any improvement ${ }^{(20)}$.

Finally, most researches have pointed out that prevention of trismus is the best option because once trismus has set it is extremely difficult to treat $(14,16,18,19,20)$

\section{PATIENTS AND METHODS}

This clinical observational study was conducted on 20 patients with confirmed newly diagnosed head and neck cancer. Patients were selected from the out patient clinics of National Cancer Institute and Nasser Institute Cancer Centre.

\section{Inclusion Criteria:}

- Pathologically proven and newly diagnosed head and neck malignancy.

- Patients 18 years or older.

- No history of previous radiation therapy.

- The maxillo-mandibular complex including the muscles of mastication and/or the temporomandibular joint were included in the field of radiation.

\section{Exclusion Criteria:}

- Malignant tumors infiltrating the temporomandibular joint and/or muscles of mastication.

- Patients suffering from temporomandibular joint derangement.

- Previous radiation therapy to the patient.

- Patients with post-surgical trismus.

\section{Maximum Interincisal Opening Measuring Pro- tocol}

Prior to the first radiation session, maximum unassisted mouth openings were measured interincisally in dentate patients and in the midline in completely edentulous patients, where the patients were sitting in an upright position. The readings were taken by a Vernier caliper, two readings were taken by different examiners to decrease the percentage of error. The same technique was used for all recorded readings during follow up.

\section{Stent Fabrication}

After the readings were recorded, the interocclusal acrylic block was fabricated in the oral and maxillofacial surgery outpatient clinic using acrylic resin. The acrylic resin is delivered in a powder and liquid form, the powder and liquid were 
mixed together in a glass bowl with the proportions recommended by the manufacturer. The mix was left till it reached the doughy stage then it was manipulated and inserted into the patient's mouth at their maximum unassisted mouth opening. The bite block was fabricated to rest on the occlusal table of the posterior teeth (premolars and molars) in dentate patients and to rest on the posterior area of the edentulous ridge in edentulous patients. The Vernier caliper was used frequently to make sure that the patients didn't decrease their mouth openings during setting of the acrylic block and a mouth gag was used to assist the patient to maintain the maximum mouth opening without decrease during setting. Then the block was finished and polished to remove any sharp edges or points that might irritate the patient during use of the block.

\section{Physiotherapy Protocol}

Patients were instructed to wear the acrylic blocks for 2 hours a day divided into 4 intervals 30 mins each distributed throughout the day for one year. Following each interval of use, patients were instructed to perform active range of mouth opening exercises for 10 cycles. These exercises were maximum mouth opening without assistance, then maximum extrusion to the right and then to the left. A full cycle is performing all three exercises.

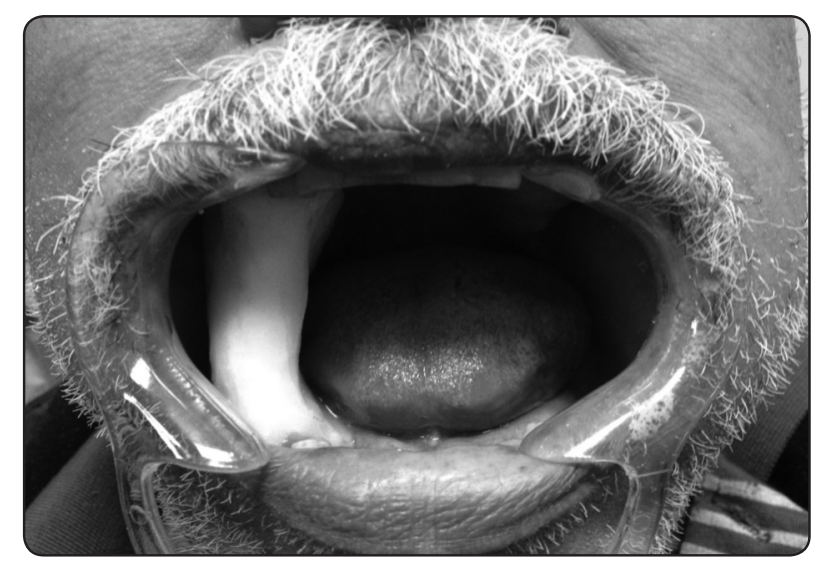

Fig. (1) Showing the Interocclusal acrylic block in place after fabrication

\section{RESULTS}

This study included 20 patients with newly diagnosed head and neck cancer undergoing radiation therapy. Patients included in this study were 15 males and 5 females with a male to female ratio 3: 1 . Ages ranged from 26 to 71 years with a mean of 51.5 years. Patient population included 18 dentate and 2 completely edentulous patients.

TABLE (1) Patient population characteristics

\begin{tabular}{|c|c|c|}
\hline & $\mathbf{N}$ & $(\%)$ \\
\hline \multicolumn{3}{|c|}{ Age } \\
\hline Median (range) & \multicolumn{2}{|c|}{56 (26-71 years) } \\
\hline \multicolumn{3}{|c|}{ Gender } \\
\hline Male & 15 & (75) \\
\hline Female & 5 & (25) \\
\hline \multicolumn{3}{|c|}{ Primary tumor site } \\
\hline Nasopharynx & 6 & (30) \\
\hline Right parotid gland & 1 & (5) \\
\hline Larynx & 2 & (10) \\
\hline Tongue & 5 & (25) \\
\hline Unknow Primary & 1 & (5) \\
\hline Left cheek & 2 & (10) \\
\hline Retromolar Triangle & 1 & $(5)$ \\
\hline Maxilla & 1 & $(5)$ \\
\hline Right Cheek & 1 & $(5)$ \\
\hline \multicolumn{3}{|c|}{ Tumor stage } \\
\hline Stage 2 & 2 & (10) \\
\hline Stage 3 & 14 & (70) \\
\hline Stage 4 & 4 & (20) \\
\hline \multicolumn{3}{|c|}{ Treatment plan } \\
\hline \multicolumn{3}{|c|}{ Non-Surgical } \\
\hline CCRT & 7 & (35) \\
\hline RT & 0 & $(0)$ \\
\hline \multicolumn{3}{|c|}{ Post-Surgical } \\
\hline CCRT & 5 & (25) \\
\hline RT & 8 & (40) \\
\hline \multicolumn{3}{|c|}{ Total Radiation Dose } \\
\hline $45 \mathrm{~Gy}$ & 1 & $(5)$ \\
\hline $60 \mathrm{~Gy}$ & 12 & (60) \\
\hline $70 \mathrm{~Gy}$ & 7 & (35) \\
\hline
\end{tabular}


Early stage malignancy was encountered in $10 \%$ of our patients while $90 \%$ were discovered with advanced stage malignancy. Tumor staging, primary tumor sites, treatment plan and total radiation doses are shown in .

Radiation doses ranged from 45 Gy to $70 \mathrm{~Gy}$. Only one patient was treated with 45 Gy in 20 fractions while 12 patients were treated with $60 \mathrm{~Gy}$ in 30 fractions and 7 patients were treated with 70 Gy where 6 of them in 33 fractions and one in 35 fractions.

Decrease in MIO was noticed as early as 4 months following completion of radiation therapy in one patient and as late as 11 months following completion of radiation therapy in 2 patients. Average $\mathrm{MIO}$ in dentate patients and edentulous patients included in this study prior to radiation therapy was $43 \mathrm{~mm}$ and $61.5 \mathrm{~mm}$ respectively and at the end of the study 12 months following completion of radiation therapy average readings were $41 \mathrm{~mm}$ and $60.5 \mathrm{~mm}$ respectively. Only one patient didn't exhibit any decrease in MIO shown in Figure 2.

Average decrease in mouth opening in dentate patients was $2 \mathrm{~mm}$ and $1 \mathrm{~mm}$ in edentulous patients. Percentage of decrease in MIO in this study was $4.9 \%$. P-value was set at $\leq 0.05$ and our results

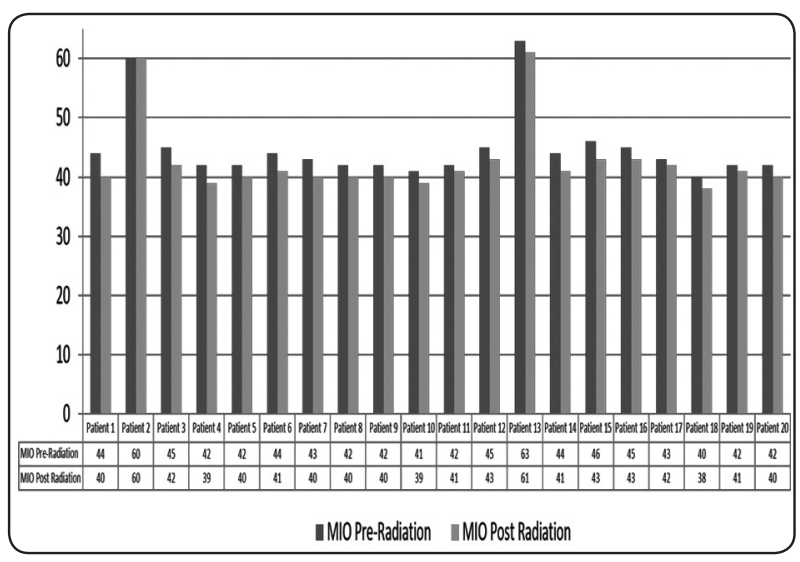

Fig. (2) MIO prior to and 12 months following completion of radiation therapy showed P-value is equal to 0.2705 which is a statistically insignificant decrease in mouth opening values and none of our patients exhibited trismus $(\mathrm{MIO} \leq 35 \mathrm{~mm}$ in dentate patients and $\leq 40 \mathrm{~mm}$ in edentulous patients).

\section{DISCUSSION}

There is a common consensus between researchers on prevention of post-radiation trismus yet there aren't enough researches on how to prevent it effectively. ${ }^{(14,16,18,19)}$ Therefore this study was aimed to prevent RT induced trismus utilizing a cost effective method rather than using costly devices such as the therabite or DTS systems.

In this study two regimens were adopted for physiotherapy; first was the use of the acrylic bite block and second was unassisted range of motion exercises. The bite block was selected for the following advantages; cheap price, customized for each patient, maintaining MIO - muscle stretching - without effort and making the patient aware that his/her MIO decreased when the bite block could not be placed in its position and required a new one to be fabricated. On the other hand, most of the patients complained from discomfort due to the hardness of the acrylic bite block. The protocol of applying the bite block was novel as this technique was not published yet. Use of the unassisted range of mouth opening exercise was to maintain muscle stretching achieved by the bite block. Unassisted range of mouth opening physiotherapy was based on a previous study by Buchbinder et al. ${ }^{(16)}$

Monthly readings were obtained from each patient because it was reported in the literature that mouth openings decrease with a rate of $2 \%-4 \%$ per month once decrease in MIO was detected. ${ }^{(4)}$

Results revealed that site of tumor and field of irradiation were relevant to decrease in MIO, where patients with laryngeal carcinoma who underwent RT showed less decrease in MIO. Since their field of radiation didn't include the TMJ, masseter and 
medial pterygoid muscles. While patients with NPC treated with CCRT showed greater degree of decrease in MIO, where their field of radiation included bilateral TMJ and maxillomandibular complex. This is consistent with other researchers who concluded that field of radiation especially inclusion of TMJ, masseter and medial pterygoid muscles is one of the most significant factors influencing incidence of trismus. ${ }^{(6,21)}$

Radiation dose is another significant predictor of RT induced trismus. Doses lower than 50 Gy have lower incidence of post RT trismus. ${ }^{(2)}$ While other researchers concluded that doses as small as 15 Gy patients exhibited trismus given that the masseter and medial pterygoid muscles were included in the radiation field. ${ }^{(6,12)}$ Our results revealed that only a single patient didn't show any decrease in MIO during follow up period and the patient received 45 Gy total dose, while all other patients received higher doses.

Studies have shown that incidence of trismus increase significantly when patients undergo both surgical and radiation therapies. ${ }^{(22,23)}$ Results in this current study didn't show such relevance, this is because of adherence and compliance of the patients -to a certain degree- to the preventive physiotherapy regimen.

A study reported the degree of decrease in the MIO following radiation was recorded at 12, 24, 36 and 48 months following completion of radiation, their results showed percentage of decrease of $26.9 \%, 30.6 \%, 31.7 \%$ and $32.2 \%$ respectively and the decrease was statistically significant ${ }^{(24)}$. Results in our study revealed that 12 months after completion of radiation the percentage of decrease in MIO was $4.9 \%$ and that was statistically insignificant decrease in mouth opening measurements and none of the patients included in this study developed trismus ( $\mathrm{MIO} \leq 35 \mathrm{~mm}$ in dentate and $\leq 40 \mathrm{~mm}$ in edentulous patients). Our results show statistical insignificance in decrease in mouth opening and better results from Wang et al research, thus our simple and cost-effective acrylic bite block shows promise to decrease the incidence of post radiation trismus.

Patient compliance and willpower are the most important factors in determining improvement of mouth opening during physiotherapy for treatment or prevention of post radiation trismus. ${ }^{(15-19)}$ The only patient that didn't exhibit any decrease in MIO even though her radiation field included the masseter and medial pterygoid muscles and had a total radiation dose of 45 Gy was committed and compliant to the physiotherapy regimen.

\section{CONCLUSION}

This observational study concluded that using the inter-occlusal acrylic bite block could actually prevent radiation induced trismus and has the added benefit of being cost effective. Utilizing recent modalities in RT such as the use of IMRT decreases the incidence of post RT trismus. The most important factor in determining improvement in treatment or prevention is patient compliance and morale. Thus, patient education prior to radiation therapy is very important, also moral and psychological support for these patients is of the same importance.

Limitations in the current study included a follow up period of 12 months following completion of RT, while other researches have a mean follow up period of 36 to 48 months since decrease in MIO following RT continue to a period of up to 4 years. Another limitation is lack of standardization regarding multiple malignancy sites leading to multiple radiation fields.

Further studies are needed to complete this technique such as longer term follow up periods, randomized controlled trials to compare different techniques and standardization of patient characteristics such as tumor site, histopathology and radiation field. 


\section{REFERENCES}

1. Fischer DJ, Epstein JB. Management of patients who have undergone head and neck cancer therapy. Dental clinics of North America. 2008;52(1):39-60.

2. Ichimura K, Tanaka T. Trismus in patients with malignant tumours in the head and neck. J Laryngol Otol. 1993;107(11):1017-20.

3. Dijkstra PU, Huisman PM, Roodenburg JL. Criteria for trismus in head and neck oncology. Int J Oral Maxillofac Surg. 2006;35(4):337-42.

4. Kent ML, Brennan MT, Noll JL, Fox PC, Burri SH, Hunter $\mathrm{JC}$, et al. Radiation-Induced trismus in head and neck cancer patients. Supportive Care in Cancer. 2008;16(3):305-9.

5. Mezitis M, Rallis G, Zachariades N. The normal range of mouth opening. Journal of oral and maxillofacial surgery : official journal of the American Association of Oral and Maxillofacial Surgeons. 1989;47(10):1028-9.

6. Goldstein M, Maxymiw WG, Cummings BJ, Wood RE. The effects of antitumor irradiation on mandibular opening and mobility: a prospective study of 58 patients. Oral surgery, oral medicine, oral pathology, oral radiology, and endodontics. 1999;88(3):365-73.

7. Bensadoun RJ, Riesenbeck D, Lockhart PB, Elting LS, Spijkervet FK, Brennan MT, et al. A systematic review of trismus induced by cancer therapies in head and neck cancer patients. Support Care Cancer. 2010;18(8):1033-8.

8. Chen YY, Zhao C, Wang J, Ma HL, Lai SZ, Liu Y, et al. Intensity-modulated radiation therapy reduces radiation-induced trismus in patients with nasopharyngeal carcinoma: a prospective study with $>5$ years of follow-up. Cancer. 2011;117(13):2910-6.

9. Teguh DN, Levendag PC, Voet P, van der Est H, Noever I, de Kruijf W, et al. Trismus in patients with oropharyngeal cancer: relationship with dose in structures of mastication apparatus. Head \& neck. 2008;30(5):622-30.

10. Kamstra JI, van Leeuwen M, Roodenburg JL, Dijkstra PU. Exercise therapy for trismus secondary to head and neck cancer: A systematic review. Head \& neck. 2016.

11. Gebre-Medhin M, Haghanegi M, Robert L, Kjellen E, Nilsson P. Dose-volume analysis of radiation-induced trismus in head and neck cancer patients. Acta Oncol. 2016;55(11):1313-7.
12. van der Molen L, Heemsbergen WD, de Jong R, van Rossum MA, Smeele LE, Rasch CR, et al. Dysphagia and trismus after concomitant chemo-Intensity-Modulated Radiation Therapy (chemo-IMRT) in advanced head and neck cancer; dose-effect relationships for swallowing and mastication structures. Radiotherapy and oncology : journal of the European Society for Therapeutic Radiology and Oncology. 2013;106(3):364-9.

13. Hsiung C, Huang E, Ting H, Huang H. Intensity-modulated radiotherapy for nasopharyngeal carcinoma: the reduction of radiation-induced trismus. The British journal of radiology. 2014(81):809-14.

14. Dijkstra PU, Kalk WW, Roodenburg JL. Trismus in head and neck oncology: a systematic review. Oral Oncol. 2004;40(9):879-89.

15. Stubblefield MD, Manfield L, Riedel ER. A Preliminary Report on the Efficacy of a Dynamic Jaw Opening Device (Dynasplint Trismus System) as Part of the Multimodal Treatment of Trismus in Patients With Head and Neck Cancer. Archives of Physical Medicine and Rehabilitation. 2010;91(8):1278-82.

16. Buchbinder D, Currivan RB, Kaplan AJ, Urken ML. Mobilization regimens for the prevention of jaw hypomobility in the radiated patient: a comparison of three techniques Journal of oral and maxillofacial surgery : official journal of the American Association of Oral and Maxillofacial Surgeons. 1993;51(8):863-7.

17. Abdel-Galil K, Anand R, Pratt C, Oeppen B, Brennan P. Trismus: an unconventional approach to treatment. The British journal of oral \& maxillofacial surgery. 2007;45(4):339-40.

18. Tang Y, Shen Q, Wang Y, Lu K, Wang Y, Peng Y. A randomized prospective study of rehabilitation therapy in the treatment of radiation-induced dysphagia and trismus. Strahlentherapie und Onkologie : Organ der Deutschen Rontgengesellschaft [et al]. 2011;187(1):39-44.

19. Melchers LJ, Van Weert E, Beurskens CHG, Reintsema $\mathrm{H}$, Slagter AP, Roodenburg JLN, et al. Exercise adherence in patients with trismus due to head and neck oncology: a qualitative study into the use of the Therabite (R). International Journal of Oral and Maxillofacial Surgery. 2009;38(9):947-54.

20. Bhrany AD, Izzard M, Wood AJ, Futran ND. Coronoidectomy for the treatment of trismus in head and neck cancer patients. Laryngoscope. 2007;117(11):1952-6. 
21. Pauli N, Olsson C, Pettersson N, Johansson M, Haugen $\mathrm{H}$, Wilderang $\mathrm{U}$, et al. Risk structures for radiationinduced trismus in head and neck cancer. Acta Oncol. 2016;55(6):788-92.

22. Lee R, Slevin N, Musgrove B, Swindell R, Molassiotis A. Prediction of post-treatment trismus in head and neck cancer patients. The British journal of oral \& maxillofacial surgery. 2012;50(4):328-32.
23. Scott B, D'souza J, Perinparajah N, Lowe D, Rogers S. Longitudinal evaluation of restricted mouth opening (trismus) in patients following primary surgery for oral and oropharyngeal squamous cell carcinoma. British Journal of Oral and Maxillofacial Surgery. 2011;49(2):106-11.

24. Wang CJ, Huang EY, Hsu HC, Chen HC, Fang FM, Hsiung $\mathrm{CY}$. The degree and time-course assessment of radiationinduced trismus occurring after radiotherapy for nasopharyngeal cancer. Laryngoscope. 2005;115(8):1458-60. 